\title{
Selective Visualization of Water in Fuel Cell Gas Diffusion Layers with Neutron Dark-Field Imaging
}

\author{
M. Siegwart, ${ }^{1,2}$ R. P. Harti, ${ }^{2}$ V. Manzi-Orezzoli, ${ }^{1}$ J. Valsecchi, ${ }^{2}$ M. Strobl, ${ }^{2}$ C. Grünzweig, ${ }^{2}$ \\ T. J. Schmidt, $1{ }^{1,3, *}$ and P. Boillat $\oplus^{1,2, z}$
}

${ }^{1}$ Electrochemistry Laboratory (LEC), Paul Scherrer Institut (PSI), Villigen, Switzerland
${ }^{2}$ Laboratory for Neutron Scattering and Imaging (LNS), Paul Scherrer Institut (PSI), Villigen, Switzerland
${ }^{3}$ Laboratory of Physical Chemistry, ETH Zürich, Switzerland

\begin{abstract}
Visualizing the water distribution in porous gas diffusion layers (GDLs) of operating polymer electrolyte fuel cells (PEFCs) is indispensable to understand the impact of water management on performance. For this purpose, neutron and X-ray transmission imaging have been used for nearly two decades. Certain limitations inherent to attenuation based imaging methods can be overcome by applying neutron dark-field imaging, which has the ability to selectively visualize structures in the micrometer size range. In this study, we compare dark-field images and transmission images of GDLs filled with water through an injection channel. The high contrast of the dark-field value between a heavy water filled and a dry GDL is suitable to reveal water distribution patterns in the GDL. The water present in the $1 \mathrm{~mm}$ wide water injection channel of the test device does not alter the dark-field signal, as this technique is selectively sensitive to microstructures. Therefore, neutron dark-field imaging can be applied for the selective analysis of the water distribution in the GDL overlapping with channel water. In addition to the selective visualization of water distributed in a GDL, we show that neutron dark-field imaging can also be used to visualize GDL damages.

(C) The Author(s) 2019. Published by ECS. This is an open access article distributed under the terms of the Creative Commons Attribution Non-Commercial No Derivatives 4.0 License (CC BY-NC-ND, http://creativecommons.org/licenses/by-nc-nd/4.0/), which permits non-commercial reuse, distribution, and reproduction in any medium, provided the original work is not changed in any way and is properly cited. For permission for commercial reuse, please email: oa @electrochem.org. [DOI: 10.1149/2.1011902jes]
\end{abstract}

(cc) BY-NC-ND

Manuscript submitted October 4, 2018; revised manuscript received January 7, 2019. Published February 1, 2019.

Polymer electrolyte fuel cells (PEFCs) are electrochemical cells which convert the chemical energy stored in hydrogen into electric power and are used for mobile (e.g. automotive) and stationary applications. The PEFC produces power from electrochemical reactions between hydrogen (the fuel) and oxygen from the air. Highly porous gas diffusion layers (GDLs) (Figure 1) made of carbon are placed between the gas flow fields and the electrodes to deliver homogenous access of the gases to the reaction sites. Optimization of water management of PEFCs is an important lever to improve performance: The electrolyte membrane needs to be humidified to have good proton conductivity, but liquid water in the GDL can block the access of gases to the reaction sites which results in a performance drop of the PEFC..$^{1-3}$ Therefore, the GDL plays a key role for improving performance of PEFCs and characterization methods to study the water distribution in GDLs are highly demanded. The GDL can be either woven or made of randomly oriented carbon fibers and has typically a porosity of $40-90 \%{ }^{4,5}$ To enhance water removal from the catalyst layer, a microporous layer (MPL) made of carbon and polytetrafluorethylene (PTFE) is often added to the GDL. Usually, the fibers of the GDL are treated to have a hydrophobic coating (PTFE or fluorinated ethylene propylene (FEP)). Figure 1 shows scanning electron microscope images of four different GDLs to illustrate the different microstructure of GDLs from different suppliers and GDLs with or without hydrophobic coating. The images in Figures 1a, 1c and 1d show GDLs from Freudenberg (Germany). While Figure 1a shows a plain GDL without any hydrophobic coating (H1410), the GDL shown in Figure 1c is a commercially available GDL with hydrophobic treatment and the GDL shown in Figure 1d has an in-house applied coating consisting of $70 \%$ wt FEP. The image shown in Figures $1 \mathrm{~b}$ shows a GDL of the type Toray-060 (Japan) without hydrophobic coating. All images of the GDLs show the random orientation of the carbon fibers and the high porosity of the GDLs.

For almost two decades, neutron and X-ray imaging have been applied for visualizing the liquid water distribution within PEFCs. $\mathrm{X}$-ray tomographic microscopy reveals the water distribution in the PEFC with high resolution, ${ }^{6,7}$ but the drawbacks of this technique are the radiation damage to fuel cell components after a certain exposure time $^{8}$ and the low transparency of typical fuel cell housing and flow

\footnotetext{
*Electrochemical Society Member.

${ }^{\mathrm{z}}$ E-mail: pierre.boillat@psi.ch
}

field materials (aluminum, steel or graphite) for X-rays, which leads to important test cell design constraints. The most severe test cell design constrain is the one for the active area. Only small cells with active areas less than $1 \mathrm{~cm}^{2}$ can be imaged with X-ray tomography, and such cells are not necessarily representative for technical fuel cells with active areas larger than $50 \mathrm{~cm}^{2}$. Neutrons are well transmitted through fuel cell housing materials and attenuation based neutron imaging provides high contrast for liquid water. The field of view for neutron transmission imaging can be chosen large enough to perform imaging of technical fuel cells. The main drawback of this technique is its lower spatial resolution. Imaging setups with resolutions better than $10 \mu \mathrm{m}$ were recently reported ${ }^{9,10}$ but their practical application for in situ fuel cell studies is limited by the intensity of the neutron flux, as the exposure time required to maintain sufficient neutron statistics increases sharply as a function of the spatial resolution ${ }^{11}$.

Despite these limitations for tomography, it is interesting to investigate several aspects of water management such as the impact of different gas diffusion materials, ${ }^{12-14}$ flow field and cell designs ${ }^{2,15-18}$ or operation conditions ${ }^{19-22}$ using neutron attenuation based (a)

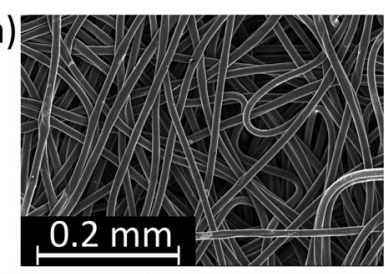

(c)

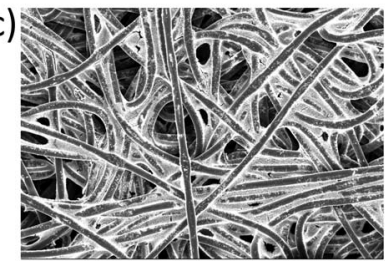

(b)

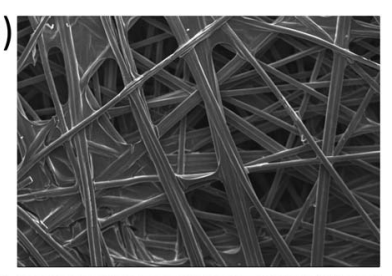

(d)

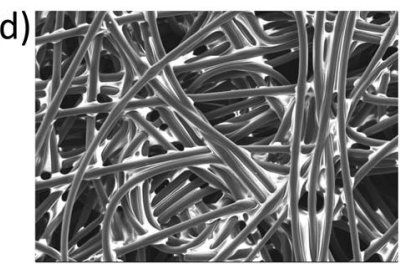

Figure 1. Scanning electron microscope images of four different GDLs: (a) Freudenberg H1410, no coating, (b) Toray-060, no coating, (c) Freudenberg H23 I2C6, commercial PTFE coating, (d) Freudenberg H23, 70\%wt FEP coating (in-house applied). 
radiography imaging. Experiments performed with the beam perpendicular to the cell membrane reveal the water thickness as an integral over all fuel cell components, but does not allow to distinguish water in individual layers. ${ }^{13}$ In order to overcome these limitations, the cell membrane can be placed parallel to the beam and the water thickness obtained in this configuration is an integral of the water in the direction along the flow field channels. This imaging configuration allows for example to visualize the difference in water distribution in different areas of the GDL (i.e. channel and rib area). ${ }^{12,23-25}$ However, to avoid saturation of the signal due to large water thicknesses, the width of the cell is limited to $20-30 \mathrm{~mm}$ in this configuration. Conventional neutron transmission imaging with the beam perpendicular to the cell allows for the distinction of water accumulated in the flow field channels and water distributed in the membrane, catalyst layers and GDLs when special purging procedures are applied. By sudden decompression of the cell, liquid water accumulated in channels is removed while it remains in the GDL. ${ }^{26}$ However, this method also has limitations. First, it can only be used with flow field designs where a large gas flow can be induced by decompression (excluding, for example, interdigitated flow fields). Second, the sudden decompression represents a risk of cell damage. And third, it can only be used to take a "snapshot" of the water distribution at a given moment, making it intrinsically a steady state analysis method.

Neutron dark-field imaging offers new possibilities to selectively study the water distribution in GDLs, as it visualizes scattering from microstructures behind materials that are opaque to light or X-rays. In general, dark-field imaging is performed with a grating interferometer designed for neutrons ${ }^{27}$ or X-rays. ${ }^{28}$ The imaging technique has been successfully applied in a broad range of applications for the analysis of microstructures such as micro-porosity in alloys ${ }^{29}$ and aluminum welds, ${ }^{30}$ or calcifications in breast tissue (cancer diagnostic) ${ }^{31}$ to name a few examples. Furthermore, it was demonstrated that directional dark-field imaging yields information about the microscopic texture such as local orientation and degree of anisotropy. ${ }^{32-35}$ Darkfield imaging can also provide 3D microstructural information in tomographic mode. ${ }^{36-38}$ Colloidal systems ${ }^{39-44}$ and powders ${ }^{45}$ were investigated with this imaging method to demonstrate its capability to provide quantitative results for example on the radius size of the colloid particles. Yang et al. ${ }^{46}$ showed that X-ray dark-field imaging is able to visualize the transport of water in thin samples $(2 \mathrm{~mm})$ of porous mortar. Here, we demonstrate the ability of neutron dark-field imaging to specifically visualize water in GDLs mounted in a test device with an aluminum thickness of approximately three centimeters, which is similar to the aluminum thickness of fuel cell test hardware. The technique is selectively sensitive to structures in the size range of one to several tens of micrometers ${ }^{29,39,40}$ which corresponds to the size of GDL fibers and pores. In order to obtain a high contrast between wet and dry GDLs (see next section) we used not only light water $\left(\mathrm{H}_{2} \mathrm{O}\right)$, but also heavy water $\left(\mathrm{D}_{2} \mathrm{O}\right)$. In fuel cell experiments, the cell can be operated with $\mathrm{D}_{2}$ to generate $\mathrm{D}_{2} \mathrm{O}$. Even though the operation with $D_{2}$ is relatively expensive, several researchers have used $D_{2} / D_{2} O$ for labeling water flows and steams in combination with isotope sensitive imaging methods, such as magnetic resonance imaging (MRI) ${ }^{47,48}$ and neutron transmission imaging. ${ }^{49-53}$ These investigations helped to understand water transport processes occurring inside the fuel cell. In general, a fuel cell fed with $\mathrm{D}_{2}$ shows comparable performance to a fuel cell fed with $\mathrm{H}_{2}$ and heavy water is suitable to represent light water in fuel cell experiments.

\section{Theoretical Background}

With a neutron grating interferometer, the conventional transmission image is obtained simultaneously to the dark-field image. Different physical phenomena are responsible for contrast in the two imaging modes.

Transmission of neutrons through material depends on how much the beam is attenuated and is described by the Beer-Lambert law:

$$
I=I_{0} e^{-N \sigma t},
$$

where $I$ is the transmitted and $I_{0}$ the incoming intensity of neutrons, $\sigma$ the total scattering cross section, $N$ the atomic number density and $t$ the thickness of the material. The total scattering cross section includes all processes that hinder neutrons from passing the material, which are coherent and incoherent scattering and absorption. The product of the total scattering cross section and atomic number density is called total attenuation coefficient. Both, the coherent and incoherent scattering cross sections depend on the nuclear potential of the material and differ for different isotopes of the same element. ${ }^{54}$ When neutrons interact with hydrogen atoms $(\mathrm{H})$, the probability for incoherent scattering is high and therefore the total attenuation coefficient for hydrogen is large. The deuterium atom (D) has a lower attenuation coefficient (due to a smaller total scattering cross section). The darkfield contrast on the other hand is not influenced by attenuation (as long as enough neutrons pass the sample) but originates from coherent scattering of neutrons to ultra-small angles by microstructures having a scattering length density (SLD) different to their surroundings. The advantage over a classical ultra-small angle neutron scattering (USANS) setup is that spatially resolved information is obtained. As described in the literature, ${ }^{29,36,37,39,40,43}$ ultra-small angle neutron scattering by the sample results in a reduction of the interference pattern amplitude produced by the grating interferometer. This amplitude divided by the mean intensity is referred to as visibility. The dark-field value (DF-value) measured for each pixel of the image is the visibility of the sample divided by the visibility of the open beam. Like the transmission value, the DF-value is always between zero and one. In case the sample does not contain materials that attenuate neutrons, transmission is equal to one and the more neutron attenuating materials are contained in the sample, the lower is the transmission. In principle, the DF-value can be described analogous to transmission. It is equal to one when the sample does not contain microstructures, and the reduction of the DF-value depends on factors influencing coherent scattering, which are: the amount, SLD contrast and form and size of microstructures. More precisely, the DF-value depends on the macroscopic scattering cross section, $\Sigma_{s}$, and the real space correlation function $G(\xi, R)$ as described by Strobl. ${ }^{43}$ For homogenous systems the relation is described as:

$$
D F-\text { value }=e^{\left(t \Sigma_{s}[(G(\xi, R)-1)]\right)} .
$$

$G(\xi, R)$ depends on the autocorrelation length $\xi$ and the effective structure size $R$ of the scatterers. For inhomogeneous systems, $\Sigma_{s}[(G(\xi, R)-1)]$ is integrated along the path of the beam through the sample thickness $t .{ }^{43}$ For a two phase system, $\Sigma_{s}$ is according to ${ }^{55}$ given by:

$$
\Sigma_{s}=\lambda^{2}\left(\Delta_{S L D}\right)^{2} \phi_{v}\left(1-\phi_{v}\right) R,
$$

where $\Delta_{S L D}$ is the difference of SLD between the two considered materials, $\lambda$ the neutron wavelength and $\phi_{v}$ the volumetric concentration of the scatterers. An essential point to note is that $\Sigma_{s}$ depends on the squared value of $\Delta_{S L D}$, which needs to be taken into account when evaluating the dark-field contrast expected from a sample.

By evaluating $\Delta_{S L D}{ }^{2}$ for the different interfaces in a water or air filled GDL, it is possible to estimate whether filling the pores of the GDL with water results in a higher or lower DF-value compared to a dry GDL. The $\Delta_{S L D}{ }^{2}$ for such a carbon fiber based GDL (without hydrophobic coating) filled completely with air, light or heavy water is evaluated in this paragraph. Schematic illustrations (Figures 2a-2e) show a GDL which is completely dry (Figure 2a), and filled with light water (Figure 2b) and heavy water (Figure 2d), respectively. In addition, the illustrations of a GDL partially filled with light water (Figure 2c) and heavy water (Figure 2e) are shown. The SLD values of the 5 media present in a dry or wet GDL are given in Figure $2 \mathrm{f}$. Compared to a dry GDL it can be expected that a fully $\mathrm{H}_{2} \mathrm{O}$ filled GDL will lead to a slightly decreased DF-value (increased scattering signal) due to a larger $\Delta_{S L D}{ }^{2}$ for $\mathrm{C}-\mathrm{H}_{2} \mathrm{O}$ interfaces compared to C-air (Figure $2 \mathrm{~g}$ ). In contrast, a completely $\mathrm{D}_{2} \mathrm{O}$ filled GDL is expected to result in a significantly higher DF-value (decreased scattering signal) due to a much smaller $\Delta_{S L D}{ }^{2}$ (Figure $2 \mathrm{~g}$ ). In case the GDL is only partially filled with heavy water $\left(\mathrm{D}_{2} \mathrm{O}\right)$, we are considering a system 
(a) Dry

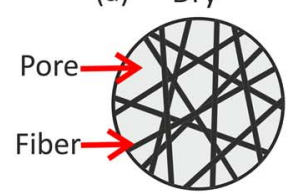

Completly filled

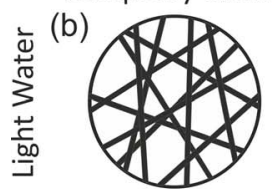

(d)

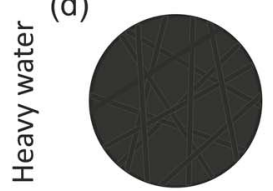

Partially filled

(c)

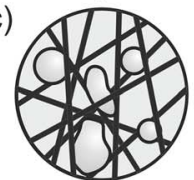

(e)

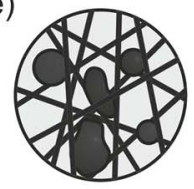

(f)

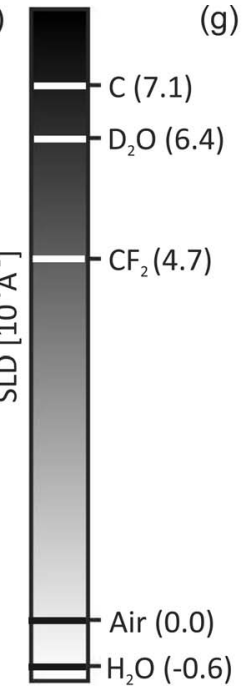

(g)

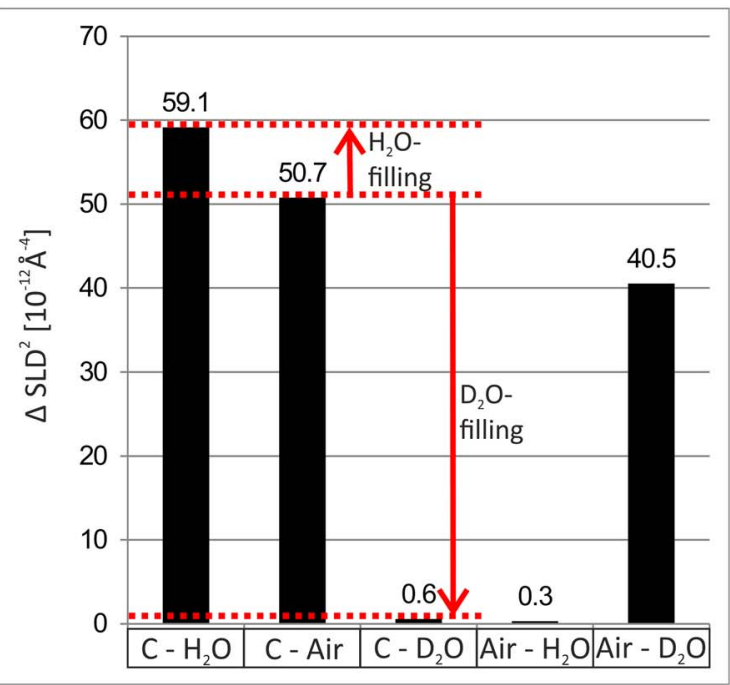

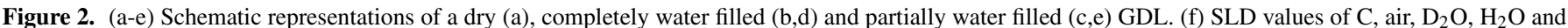

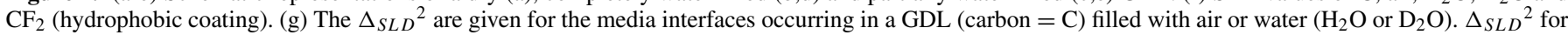
interfaces with $\mathrm{CF}_{2}$ are not shown for the sake of conciseness.

with three phases and estimations about the resulting DF-value are not straightforward: it depends on the amount of additional air- $\mathrm{D}_{2} \mathrm{O}$ interfaces due to droplets. A large amount of small droplets might lead to a decreased DF-value due to the significant $\Delta_{S L D}{ }^{2}$ value for air- $\mathrm{D}_{2} \mathrm{O}$, while large heavy water accumulations, which have more contact with carbon fibers than with the air, are expected to result in an increased DF-value compared to the dry GDL. On the contrary, the $\mathrm{H}_{2} \mathrm{O}$-air interfaces present in a partially $\mathrm{H}_{2} \mathrm{O}$ filled GDL are expected to have a negligible impact. The DF-value of GDLs with hydrophobic coating might be different compared to samples without coating. Adding coating around the fibers could decrease the DF-value due to additional interfaces of $\mathrm{CF}_{2}-\mathrm{C}$, but on the other hand $\Delta_{S L D}{ }^{2}$ for $\mathrm{CF}_{2}-$ air is smaller compared to $\mathrm{C}$-air. Therefore, a decrease in scattering signal (higher DF-value) could also be possible.

\section{Experimental}

Materials and devices.-An in-house constructed aluminum test device was used to fill the GDLs by water injection and dry them by evaporation without removing them from the beam. The test device contained two channels with a width and depth of $1 \mathrm{~mm}$. The GDLs were placed on top of these two channels and the system was sealed with a gasket. The water channel was covered by a $5 \mathrm{~mm}$ wide hydrophilic porous membrane (PM) and water was brought to the GDLs by applying pressure to the water in the channel (up to 0.2 bar relative pressure). The second channel was used to dry the GDLs by evaporation. This channel was covered by a hydrophobic PM to prevent water invading the channel but allowing drying of the GDL

\begin{tabular}{|c|c|c|c|c|}
\hline GDL type & Toray TGP-H-060 & \multicolumn{3}{|c|}{ Freudenberg H23 } \\
\hline $\begin{array}{l}\text { In-house applied FEP } \\
\text { coating/wt } \%\end{array}$ & 0 & 0 & 30 & 70 \\
\hline Abbreviation & T00 & F00 & F30 & $\mathrm{F} 7$ \\
\hline
\end{tabular}

by letting water vapor diffuse through it. The tested GDLs were all without micro-porous layers (MPLs) and are displayed in Table I.

Two different concepts were used for sealing: The data presented in Figures 3-8 were acquired in experiments where a steel spacer with an O-ring gasket was used. The experimental results presented in Figure 9 and Figure 10 were obtained by using a rubber gasket for sealing. The GDLs had an area of $2 \times 2.2 \mathrm{~cm}^{2}$ and the test device was designed to compress the GDLs to $160 \mu \mathrm{m}$, which is about $75 \%$ of their original thickness. Schematics of the experimental setup are shown in Figure $4 \mathrm{a}$ and Figure $4 \mathrm{~b}$.

Drying and water filling procedures.-First, images of all samples in the dry state were obtained. After the GDLs were filled with water by pressuring the water in the channel up to 0.2 bar for three minutes, images of the almost fully water filled GDLs were taken. These images are later referred to as the water filled images. Afterwards, the water channel was purged with dry air to remove the water in the channel and subsequently the GDLs were dried with a steady gas flow through the gas channel of $4 \mathrm{Lmin}^{-1}$ for 8 minutes. After this first drying step another set of images were acquired referred to as drying step 1 . The next two drying phases (drying step 2 and drying step 3) took
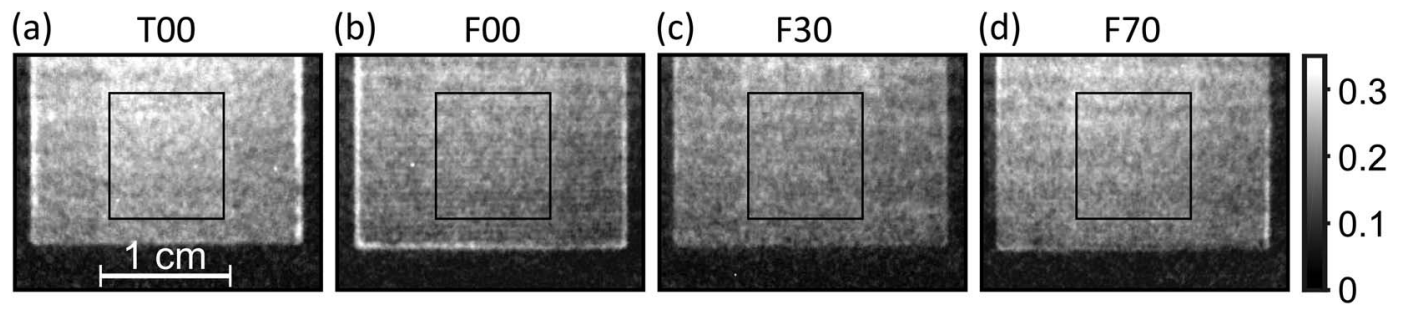

Figure 3. Dark-filed images of four different dry GDL samples. (a) Toray-060 without coating (T00). (b-d) Freudenberg H23: (a) without coating (F00), (b) with $30 \%$ wt (F30) and (c) with 70\% wt (F70) in-house applied FEP coating. The black rectangles indicate the area for which the mean DF-value and standard deviation is calculated and given in the text. 

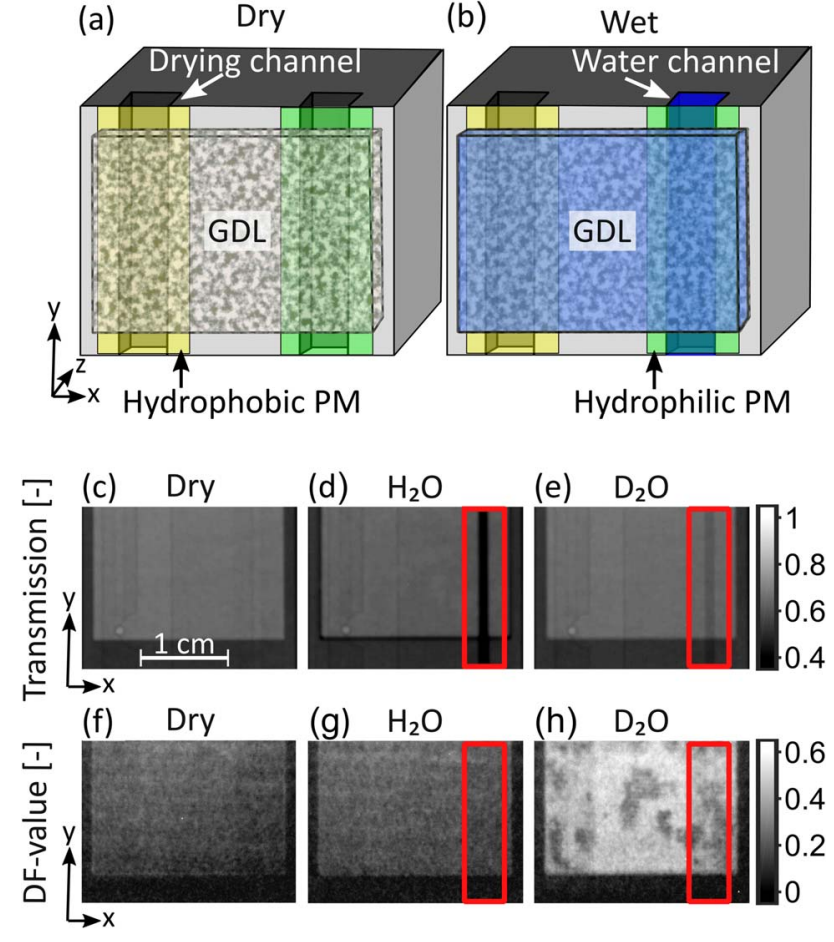

Figure 4. Schematics of the experimental setup with (a) empty water channel and GDL, (b) water filled channel and GDL. The channels are $1 \mathrm{~mm}$ wide and deep. The hydrophilic and hydrophobic porous membranes (PMs) are $5 \mathrm{~mm}$ wide and are shown above the water and drying channel, respectively. Schematics of setup are not to scale with the images. (c-e) Transmission images and (f-h) dark-field images of a GDL (F30): (c,f) Dry, (d,g) $\mathrm{H}_{2} \mathrm{O}$-filled, (e,h) $\mathrm{D}_{2} \mathrm{O}$-filled.

another 8 minutes each followed by a break for imaging acquisition. The drying was only successful for the Freudenberg GDL with inhouse applied FEP coating of $70 \mathrm{wt} \%$ (F70). For the other samples, water accumulations between the GDL and the spacer frame impeded drying in a suitable time frame with simultaneous imaging. For this reason we only present here results from all samples after the water filling step, and results for the drying procedure for GDL F70. Even though GDLs with less hydrophobic coating are more common for fuel cell applications, GDLs with high hydrophobic coating loads gained of interest recently as they are better suited for modifications (i.e. to produce patterns of hydrophilic and hydrophobic regions. ${ }^{56,57}$

Neutron dark-field and transmission imaging.-The experiments were performed at the ICON beamline ${ }^{58}$ at the Swiss Spallation Neutron Source (SINQ) with a neutron grating interferometer which consists of three gratings termed G0, G1 and G2. G0 is an absorption grating with a period of $1076 \mu \mathrm{m}$ which provides coherence. To fabricate this grating Gadolinium is sputtered onto a Quartz wafer and slits are lasered into the Gadolinium. G1 is called "phase grating" and has a period of $7.97 \mu \mathrm{m}$. It is fabricated on a Silicon wafer and introduces a $\pi$-phase shift to the neutron wave. G2 is another absorption grating, which is put at the Talbot distance from G1 in front of the scintillator. The absorbing lines of $\mathrm{G} 2$ are fabricated by Gadolinium evaporation onto a Quartz wafer. For detailed description of the interferometer see previously published papers. ${ }^{27,39}$ The setup was used with the first Talbot distance of $19.4 \mathrm{~mm}$ and a wavelength of $4.1 \AA(\Delta \lambda / \lambda=15 \%)$, and 21 phase stepping images were acquired per interference period each with an exposure time of $75 \mathrm{~s}$. The images were acquired with a conventional imaging setup using a sCMOS camera (Andor Neo) and a $200 \mu \mathrm{m}$ thick ${ }^{6} \mathrm{LiF} / \mathrm{ZnS}$ scintillator.

Image processing.-Data processing was performed with the inhouse software TaPy. ${ }^{59}$ After subtracting the dark current value of the camera pixel-wise from the images, outlier removal was performed to filter out bright spots which are for example produced when $\gamma$-Rays hit the chip of the detector. TaPy retrieves for every pixel the amplitude and offset of the sinusoidal intensity variation over the phase stepping images taken with the open beam and the sample. The dark-field and transmission images are then obtained based on the ratio of the amplitude and offset between sample and open beam images, respectively.

\section{Results and Discussion}

Visualizing water in GDLs.-In Figure 3 the dark-field images of four different dry GDL samples (Table I) are shown. The black rectangles indicate the area for which the mean DF-value and standard deviation is calculated. The first sample is a GDL of type Toray-060 without coating (Figures 3a) and the next three GDLs are Freudenberg H23 with different hydrophobic coating loads (Figures 3b-3d). The mean DF-value is between 0.2 and 0.3 for all samples, and - as expected based on the considerations made in the theoretical background section - it differs slightly for different type of GDLs and for different coating loads. The trend shows that the lowest DF-value $(0.23 \pm 0.04)$ is measured for F00 and the higher the FEP coating load, the higher the DF-value with $0.24 \pm 0.05$ for F30 and $0.27 \pm 0.05$ for F70. This indicates that the coating-air interfaces (lower $\Delta_{S L D}{ }^{2}$ for $\mathrm{CF}_{2}$-air compared to $\mathrm{C}$-air) influence the $\mathrm{DF}$-value more than the additional coating-carbon interfaces. T00 has a higher DF-value $(0.27 \pm 0.05)$ compared to F00. This difference might be attributed to all the microstructural differences between the two samples which are mainly porosity, pore shape and size, binder or carbon density. In summary, the DF-value differs for different GDL types and coating loads but it is for all samples in a range where it is possible to perform experiments as dark-field contrast is present, but the signal does not saturate due to too much contrast.

Figure 4 contains the schematics of the experimental setup (Figures $4 \mathrm{a}$ and $4 \mathrm{~b}$ ), transmission images (Figures $4 \mathrm{c}-4 \mathrm{e}$ ) and dark-field images (Figures $4 \mathrm{f}-4 \mathrm{~h}$ ) of the GDL F30 (dry and water filled). The images of the dry GDL were taken when the water filling channel was empty (Figures $4 \mathrm{a}, 4 \mathrm{c}$ and $4 \mathrm{f}$ ) while the wet GDL was imaged with a water filled channel (Figures 4b, 4d, 4e, 4g and 4h).

The transmission images of the dry (Figure 4c) and water filled (Figures 4d and 4e) GDL mostly differ in the area of the water channel where a stronger attenuation due to water leads to a reduced transmission value (more pronounced for light than for heavy water due to the higher attenuation coefficient). By comparing the dark-field image of the dry (Figure 4f) and heavy water filled (Figure 4h) GDL, it is clearly apparent that the DF-value is significantly higher for the water filled GDL over the whole GDL area. For light water (Figure 4g) no difference between the dry and wet GDL is apparent for the dark-filed images without referencing.

For a better visualization of the effect of filling GDL pores with water, the water distribution in the GDL sample of type F30 is shown with a water thickness image (WTI) calculated from transmission (Figure 5a) and DF-value difference images (Figures 5b) for light water. The same images for heavy water are shown in Figures $5 \mathrm{c}$ and $5 \mathrm{~d}$. The WTIs are calculated with the Beer-Lambert law (Equation 1) from the transmission values. An attenuation coefficient of $5.4 \mathrm{~cm}^{-160}$ for $\mathrm{H}_{2} \mathrm{O}$ and $0.70 \mathrm{~cm}^{-161}$ for $\mathrm{D}_{2} \mathrm{O}$ was used, corresponding to a neutron wavelength of $4.1 \AA$. A color scale is shown for each type of image and emphasizes where the GDL is dry (yellow) and where water is present (blue). The black line around the GDL in the images illustrates the border of the GDL for a simplified comparison between the images. The profile of the water thickness and DF-value in the area between the dashed red lines is shown below the images. In the DF-value difference image for light water (Figure 5b), a negative color scale is used as filling the GDL with $\mathrm{H}_{2} \mathrm{O}$ results in a lower DF-value. On the other hand, the $\mathrm{D}_{2} \mathrm{O}$ filled GDL (Figure 5d) shows a higher DF-value compared to the air filled GDL, which is shown using a 


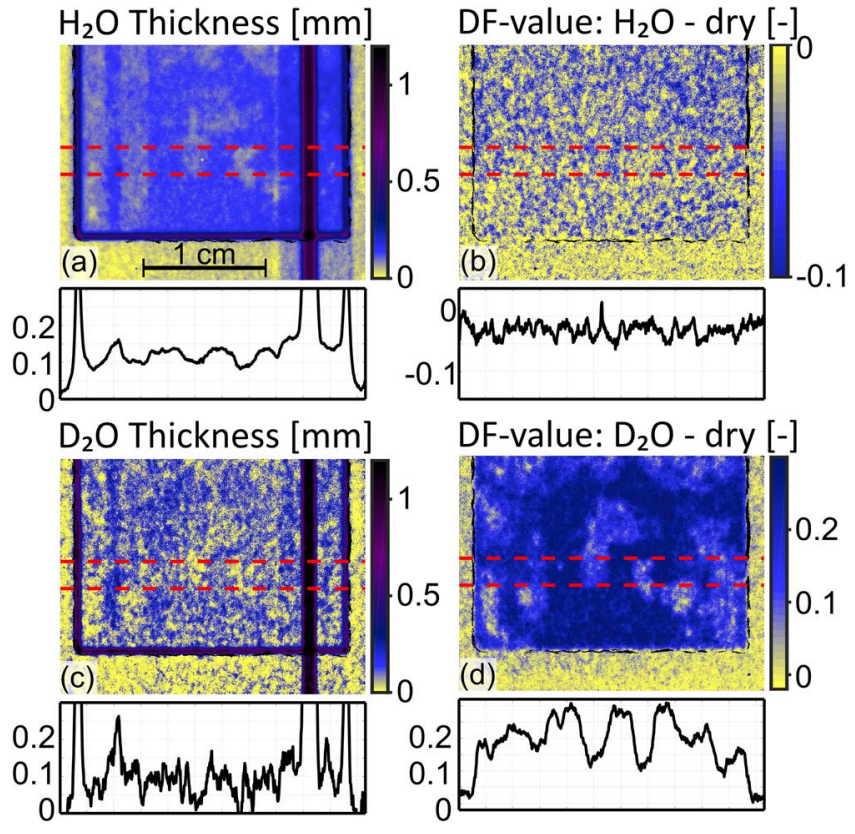

Figure 5. Color coded images showing the water distribution in the GDL sample F30. Color code: yellow $=$ dry, blue $=$ water present. Water thickness images (WTIs) calculated from transmission images: (a) $\mathrm{H}_{2} \mathrm{O}$, (c) $\mathrm{D}_{2} \mathrm{O}$. Difference of DF-value between wet and dry state of the test device and GDL: (b) $\mathrm{H}_{2} \mathrm{O}$, (d) $\mathrm{D}_{2} \mathrm{O}$. The dashed red lines in the images indicate the area for which the profile is plotted.

positive color scale. This behavior of the DF-value is consistent with the expectations discussed in the section Theoretical background.

The most important difference between water thickness images (Figures $5 \mathrm{a}$ and $5 \mathrm{c}$ ) and DF-value difference images (Figures $5 \mathrm{~b}$ and 5d) is that, as expected, the filled water channel does not appear in the DF difference images. In regions of the GDL which are not overlapping with the water channel, the water distribution can be visualized with both transmission and dark-filed imaging. However, there are considerable differences of the contrast-to-noise ratio between the four images. The attenuation coefficient for $\mathrm{H}_{2} \mathrm{O}$ is high and even thin layers of light water result in a significant contrast. Therefore, the noise of the light water thickness calculated based on a transmission image (Figure 5a) is low. Similarly, the DF-value difference between a GDL filled with air and heavy water (Figure 5d) also results in little noise due to the contrast generating property $\Delta_{S L D}{ }^{2}$, which is significantly different for $\mathrm{C}-\mathrm{D}_{2} \mathrm{O}$ compared to C-air (see Figure 2). On the other hand, the attenuation coefficient of $\mathrm{D}_{2} \mathrm{O}$ is low and, therefore, the water thickness calculated based on the transmission image of the heavy water filled GDL (Figure 5c) is afflicted with much noise. The same applies to the DF difference image for light water (Figure $5 b$ ), because the value of $\Delta_{S L D}{ }^{2}$ is only slightly different for $\mathrm{C}-\mathrm{H}_{2} \mathrm{O}$ in comparison to $\mathrm{C}$-air (Figure 2). When using light water, the decrease of the DF-value between the water filled and dry GDL amounts only to 0.03 (Figure $5 \mathrm{~b}$ and Table II). Because of this low contrast, a reliable

Table II. Average water thickness and DF-value difference between wet and dry GDL for T00, F00, F30 and F70 in the area of the red rectangle between the red dashed lines (Figure 6).

\begin{tabular}{cccc} 
& $\begin{array}{c}\text { Water thickness } \\
\left(\mathrm{H}_{2} \mathrm{O}\right)[\mathrm{mm}]\end{array}$ & $\begin{array}{c}\text { DF-value: } \\
\mathrm{H}_{2} \mathrm{O}-\text { dry }[-]\end{array}$ & $\begin{array}{c}\text { DF-value: } \\
\mathrm{D}_{2} \mathrm{O}-\text { dry }[-]\end{array}$ \\
\hline T00 & 0.14 & -0.01 & 0.21 \\
F00 & 0.15 & -0.04 & 0.27 \\
F30 & 0.13 & -0.03 & 0.27 \\
F70 & 0.12 & -0.02 & 0.10
\end{tabular}

distinction between dry and light water filled GDL areas is not possible with the current neutron grating interferometer setup, but there is potential for obtaining a better contrast-to-noise ratio. Noise of the DF-signal could be reduced by improving the fabrication process for the absorption grating (G2), ${ }^{62}$ by elongating the exposure time, by using a stronger neutron source (e.g. the upcoming European Spallation Source (ESS) in Sweden), or by filtering at the cost of a reduced spatial resolution. As mentioned, the transmission image based water thickness image with $\mathrm{D}_{2} \mathrm{O}$ suffers from a low contrast-to-noise ratio and the water distribution patterns can hardly be identified. However, comparing the $\mathrm{H}_{2} \mathrm{O}$ thickness image (Figure 5a) with the DF-value difference image between $\mathrm{D}_{2} \mathrm{O}$ filled and dry state of the test device and GDL (Figure 5d), it becomes evident that the water distribution patterns in the GDL are very similar. Apparently, water found some preferential pathways and locations in the GDLs to accumulate in a similar way in the two experiments. Filling the GDLs with water $\left(\mathrm{H}_{2} \mathrm{O}\right)$, drying them and filling them subsequently again with water $\left(\mathrm{D}_{2} \mathrm{O}\right)$ thus resulted in reproducible accumulation patterns. Therefore, the DF-value difference images between $\mathrm{D}_{2} \mathrm{O}$ and dry GDLs are hereafter compared to the $\mathrm{H}_{2} \mathrm{O}$ thickness images for all samples (Figures 6). As mentioned above, this comparison makes it evident that some general water distribution patterns are captured by both imaging techniques in the same manner: Very similar water patterns can be observed in the water thickness images of GDL F00 and F30 (Figures 6b and 6c) and in the DF-value difference images of these GDLs (Figures $6 f$ and $6 \mathrm{~g}$ ). This observation gives evidence that the heavy water distribution in the GDLs can be clearly visualized by using dark-field imaging.

Table II gives an overview on the measured water thickness $\left(\mathrm{H}_{2} \mathrm{O}\right)$ and DF-value difference between wet and dry GDL for T00, F00, F30 and F70. The values in Table II are averaged over the GDL area within the red squares (Figure 6). This area was chosen because it is not overlapping with the porous membranes and for all samples well filled with water.

The lower water thickness of the GDLs with coating can be explained with lower porosities compared to the plain materials, and by the fact that the used water pressure might not have been high enough to fill the smallest hydrophobic pores. For all four samples a substantial DF-value difference (Figures 6e-6h) is measured: The average DF-value difference between the heavy water filled and dry GDLs amounts to 0.27 for F00 and F30, 0.21 for T00 and the lowest DF-value difference is with 0.1 measured for F70 (Table II). The water thicknesses and DF-value differences do not scale directly. For F70 and F30, a very similar water thickness of $0.12 \mathrm{~mm}$ and $0.13 \mathrm{~mm}$ is measured, but the DF-value difference is considerable smaller for F70. This result indicates that the amount of hydrophobic coating influences the DF-value difference for $\mathrm{D}_{2} \mathrm{O}$ filled GDLs and was expected based on the considerations made in the theoretical background section. Equations 2 and 3 show that not only the water thickness, but also the amount and type of media interfaces $(\triangle S L D)$ and form and size of microstructures influence the DF-value. Therefore, different reasons or a combination of them can explain why water thickness and DFvalue difference do not scale linearly: First, more $\mathrm{CF}_{2}-\mathrm{D}_{2} \mathrm{O}$ instead of $\mathrm{C}-\mathrm{D}_{2} \mathrm{O}$ interfaces might be present. Second, a more hydrophobic GDL structure might lead to water filling patterns with more air- $\mathrm{D}_{2} \mathrm{O}$ and air- $\mathrm{C}$ interfaces. All three interfaces (air- $\mathrm{C}$, air- $\mathrm{D}_{2} \mathrm{O}$ and $\mathrm{CF}_{2}-\mathrm{D}_{2} \mathrm{O}$ ) have a higher $\Delta_{S L D}{ }^{2}$ compared to $\mathrm{C}-\mathrm{D}_{2} \mathrm{O}$ interfaces and would therefore result in a lower DF-value difference. Third, the coating might also influence the size and shape of water droplets in the porous GDL.

As already mentioned above, the comparison between WTIs and DF-value difference $\left(\mathrm{D}_{2} \mathrm{O}\right.$ - dry) images is most interesting for the GDL samples F00 (Figures 6b and 6f) and F30 (Figures 6c and 6g), because it reveals at first glance that some water distribution patterns are visualized by both imaging techniques. However, a detailed analysis demonstrates how the two techniques can be used to obtain complementary information and is therefore presented below, first for F00 and then for F30. The GDL sample F00 (Figures $6 \mathrm{~b}$ and $6 \mathrm{f}$ ) is dry in some areas. Despite or because of this inhomogeneous water distribution, GDL F00 most obviously demonstrates the advantage 

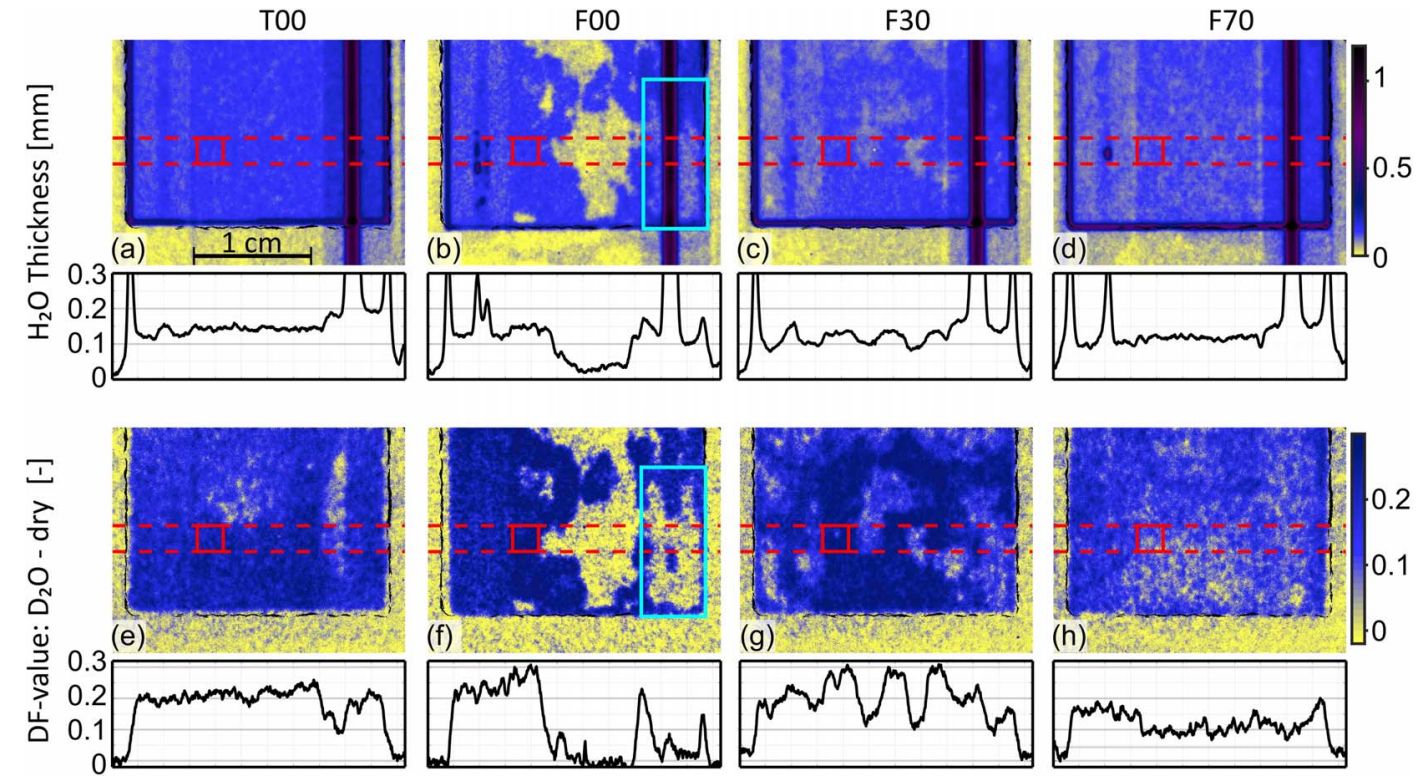

Figure 6. Color coded images showing the water distribution in T00, F00, F30 and F70. Color code: yellow $=$ dry, blue $=$ water present. $(\mathrm{a}-\mathrm{d}) \mathrm{Water}\left(\mathrm{H}_{2} \mathrm{O}\right)$ thickness images (WTIs) calculated from transmission images. (e-h) Difference of DF-value between wet $\left(\mathrm{D}_{2} \mathrm{O}\right.$-filled) and dry state of the test device and GDL. The dashed red lines in the images indicate the area for which the profile is plotted below the images, and the red rectangles indicate the area for which the average is given in Table II. The turquoise rectangle in (b) and (f) highlight an interesting area of sample F00 (see text).

of dark-field imaging over transmission imaging for the analysis of GDL water overlapping with water accumulations in channels with dimensions common for fuel cells. The WTI of GDL F00 and the line profile (Figure 6b) show that part of the GDL area (highlighted with the turquoise box), which is overlapping with the hydrophilic $\mathrm{PM}$, is sparsely filled with water. Most of the water thickness measured in that region can probably be attributed to water located in the hydrophilic PM. Not only does the water in the pores of the PM complicate the analysis of the water distribution in the GDL, but also the strong signal of water present in the channel makes it impossible to draw conclusions on the water content in the GDL area overlapping with the channel. From the DF-value difference image (Figure $6 \mathrm{f}$ ) one can conclude that most of the GDL area highlighted with the turquoise box is dry or sparsely filled with water. Neither the water in the channel nor that in the small pores of the PM (average pore diameter is $0.22 \mu \mathrm{m}^{63}$ ) interferes with the analysis of the GDL water, because the dark-field signal of the specific setup used is only sensitive to microstructures with sizes of around a few micrometers, and neither the diameter of the pores of the PM nor the channel width are within this size range. In contrast to F00, the GDL sample F30 (Figures 6c and $6 \mathrm{~g}$ ) has very few completely dry areas, but also for F30 the water distribution is quite inhomogeneous and some areas are more filled than others. As depicted in the line profile the water thickness (Figure $6 \mathrm{c}$ ) is about $0.14 \mathrm{~mm}$ in water saturated GDL areas and in areas with less water it is about $29 \%$ lower $(0.1 \mathrm{~mm})$. The DF-value difference (Figure $6 \mathrm{~g}$ ) has a value of 0.3 in completely water filled areas, while in drier GDL areas it is about $67 \%$ lower and amounts only to 0.1 . The same three explanations, which were used above in the discussion about the smaller DF-value difference measured for F70 compared to F30, can be employed here to explain why the DF-value does not scale linearly with the water thickness: First, the coating distribution in the GDL sample F30 could be inhomogeneous and in some locations there might be more $\mathrm{CF}_{2}-\mathrm{D}_{2} \mathrm{O}$ interfaces present. Second, the DF-value is sensitive to the amount of interfaces between different media. In cases where part of the pores are free of water or air bubbles are trapped in water filled pores, air- $\mathrm{C}$ as well as air- $\mathrm{D}_{2} \mathrm{O}$ interfaces are expected to be more abundant compared to water saturated GDL areas, which are dominated by $\mathrm{C}-\mathrm{D}_{2} \mathrm{O}$ interfaces. Both interfaces contribute with a large $\Delta_{S L D}{ }^{2}$ to dark-field signal (which leads to a lower DF-value) and the amount of surfaces does not scale linearly with the water thickness. As a third possible explanation we should mention again that the size and shape of water clusters influence the dark-field signal and water clusters distributed in drier areas might have a different microstructure compared to those in water saturated regions.

In summary, all samples displayed in Figure 6 show the most important difference between WTIs (Figures 6a-6d) and DF-value difference images (Figures 6e-6h): water in the $1 \mathrm{~mm}$ wide channel used for filling the GDL with water contributes to a strong signal in the WTIs obtained from transmission imaging, whereas it does not appear in the images obtained with dark-field imaging. This is even more clearly illustrated with Figure 7 where the WTIs and DF-value difference images for the drying procedure of F70 is shown. For details of the drying procedure see the experimental section. Figures 7 contains the WTIs for light water (Figures $7 \mathrm{a}-7 \mathrm{~d}$ ) and the DF-value difference images (wet - dry) for heavy water (Figures $7 \mathrm{e}-7 \mathrm{~h}$ ) in the top and bottom row, respectively. The images after the water filling process in Figure 7a and Figure $7 \mathrm{e}$ are the same as displayed in Figure $6 \mathrm{~d}$ and Figures $6 \mathrm{~h}$ for the GDL sample F70. As mentioned above, the measurement of light water thickness is more reliable compared to that of the heavy water thickness, because the latter suffers from a low contrast-to-noise ratio due to the low attenuation of heavy water. The evolution of the water distribution patterns over the drying procedure was very similar in the experiments performed with light and heavy water. Therefore, the DF-value difference images for $\mathrm{D}_{2} \mathrm{O}$ are compared here to $\mathrm{H}_{2} \mathrm{O}$ WTIs. From the WTIs (Figures 7a-7d) the evolution of the water thickness in the GDL over the drying procedure can be observed: After the first step (water filling) the channel is full of water and the GDL is well filled with water (Figure 7a). After purging the channel with dry air (drying step 1) the channel is almost empty and the GDL is less filled (Figure $7 \mathrm{~b}$ ). The next drying step (drying step 2) results in almost no change for the light water thickness (Figure 7c). After drying step 3 the water thickness in the GDL is clearly decreased (Figure 7d) compared to the previous step (Figure 7c). The water channel was not completely empty after purging and a small amount of water evaporated, redistributed and condensed again over the period of the drying protocol at the location of sample F70 (Figure 7d). In contrast to the WTIs, emptying the water channel does not affect the DF-value (Figure 7f). There is no difference in the channel area between the water filled image and drying step 1 . This confirms that water in the channel 

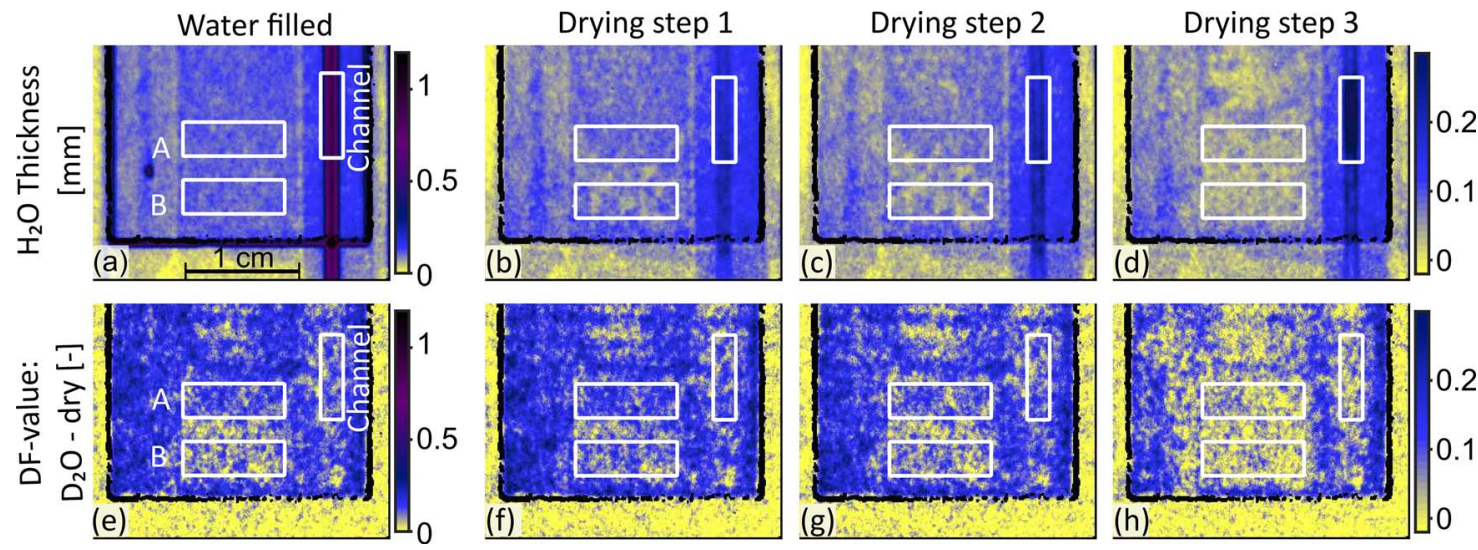

Figure 7. Image sequences over a drying procedure of the GDL sample F70. Top: Light water thickness $\left(\mathrm{H}_{2} \mathrm{O}\right)$, Bottom: DF-value difference between wet $\left(\mathrm{D}_{2} \mathrm{O}\right.$-filled) and dry state of the test device and GDL. White boxes indicate the areas for which the average is calculated and displayed in Figure 8.

does not influence the DF-value difference between wet and dry state of the test device and GDL. The dark-field difference images after the first two drying steps (Figures $7 \mathrm{f}$ and $7 \mathrm{~g}$ ) do not change significantly compared to that of the water filled case. Only after the last drying step (drying step 3), a clear decrease in the DF-value difference (Figure $7 \mathrm{~h}$ ) is visible. These findings are presented in a more quantitative manner in Figure 8. It depicts the development of the mean values for the three areas (channel area, GDL areas A and B) indicated in Figure 7 for light water thickness and DF-value difference (based on heavy water).

The water thickness and DF-value (wet - dry) evolution over the drying procedure differ mainly in two ways: The first important observation is that the water thickness in the channel area increases to a value greater than $1 \mathrm{~mm}$ for the fully water-filled state (Figure 8a),

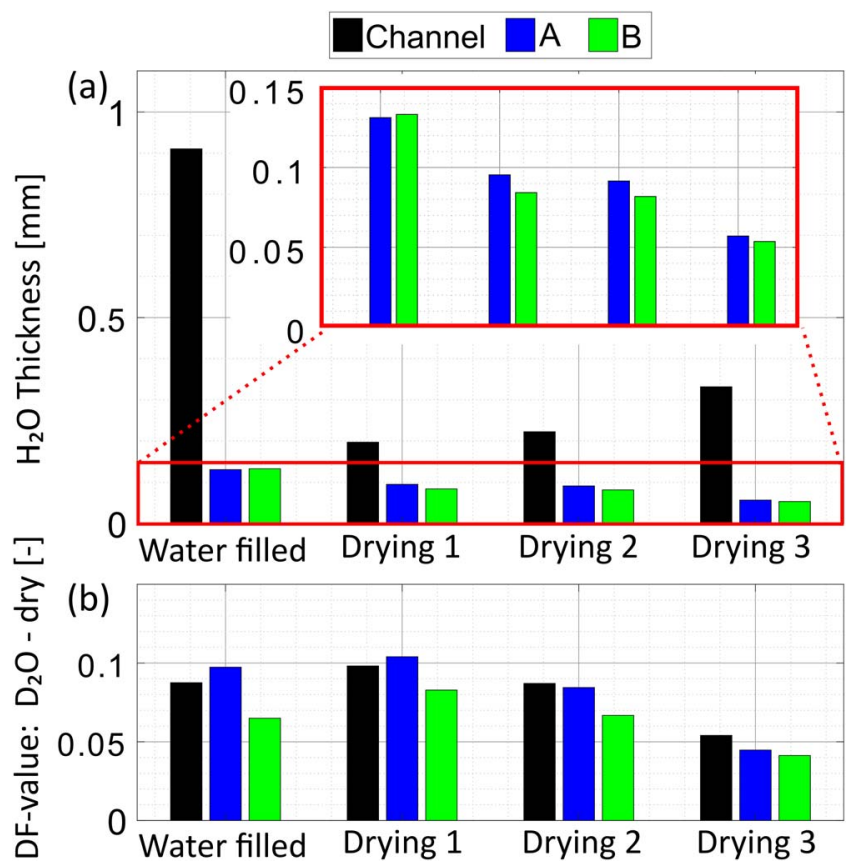

Figure 8. Quantitative representations of average water thickness and DF-value difference in areas indicated in Figure 7 with white boxes (in water channel, and in two areas (A and B) not overlapping with water channel) over drying procedure of GDL F70: (a) Average water $\left(\mathrm{H}_{2} \mathrm{O}\right)$ thickness calculated based on transmission of all three areas. Inset shows a zoom between $0 \mathrm{~mm}$ and $0.2 \mathrm{~mm}$ to visualize the change in water thickness in area A and B (not overlapping with the channel). (b) DF-value difference between wet $\left(\mathrm{D}_{2} \mathrm{O}\right.$-filled) and dry state of the test device and GDL of all three areas. while the DF value difference in the channel area is in the same range as that for the GDL areas A and B (Figure 8b). The second important point is that the water thickness and DF-value difference in the GDL develop differently during the drying procedure. The light water thickness in the GDL (Figure 8a) amounts to 0.13-0.14 mm after the water filling step and decreases to around $0.1 \mathrm{~mm}$ after drying step 1 . After drying step 3 it is further reduced to around $0.05-0.06 \mathrm{~mm}$. The DF-value difference on the other hand increases slightly after drying step 1 . It is somewhat reduced after drying step 2, and then further reduced to around half of its original value after drying step 3 . Additional air- $\mathrm{D}_{2} \mathrm{O}$ and $\mathrm{C}-\mathrm{D}_{2} \mathrm{O}$ interfaces and/or the change of the size and form of water droplets (see Equations 2 and 3 ) can explain why water thickness and DF-value difference evolve differently over time. In future experiments, the grating interferometer setup parameters will be varied during the experiment to probe different autocorrelation lengths $(\xi) .{ }^{40}$ Such studies allow for obtaining more information on the water microstructure.

In fuel cell experiments, the water saturation of the GDL under regular operation conditions is not higher than 50\%. ${ }^{6}$ From the experiments presented here, the water saturation level cannot be calculated precisely as the porosity and exact compression ratio of the GDLs is not known and it is not possible to quantify precisely the water thickness in tens of micrometers using transmission imaging due to biases (scattered background, fluctuating beam intensity). However, with a water thickness of 50-60 $\mu \mathrm{m}$ after drying step 3 and a compressed GDL thickness of at least $160 \mu \mathrm{m}$ or higher, it can be assumed that the water saturation is around $50 \%$. We can infer from the above reasoning that a difference for the DF-value should be obtained between the dry GDL and the sample filled with heavy water at GDL water saturation levels comparable to conditions in fuel cell operando experiments. This leads to the expectation that using dark-field imaging, the selective visualization of GDL water during fuel cell operation is possible. In summary, we demonstrated in this section that a significant contrast between a dry and heavy water filled GDL is obtained, and water present in a $1 \mathrm{~mm}$ wide channel does not alter the DFvalue. Therefore, neutron dark-field imaging allows for an analysis of the water distribution in the microstructure over the whole area of the GDL without an overlapping and disturbing signal from water in channels. For the experiments presented here we used a setup with only one channel where water was accumulating. For real fuel cell experiments, flow fields are used to distribute the reactant gases and half of the GDL area is overlapping with channels where water can accumulate. A reliable correlation between the DF-value and the amount of water in the GDL has yet to be demonstrated. Nevertheless, these experiments demonstrate that, at least when heavy water is used, the presence of water in the GDL can be detected even when it is overlapping with a large accumulation of water in a channel. 


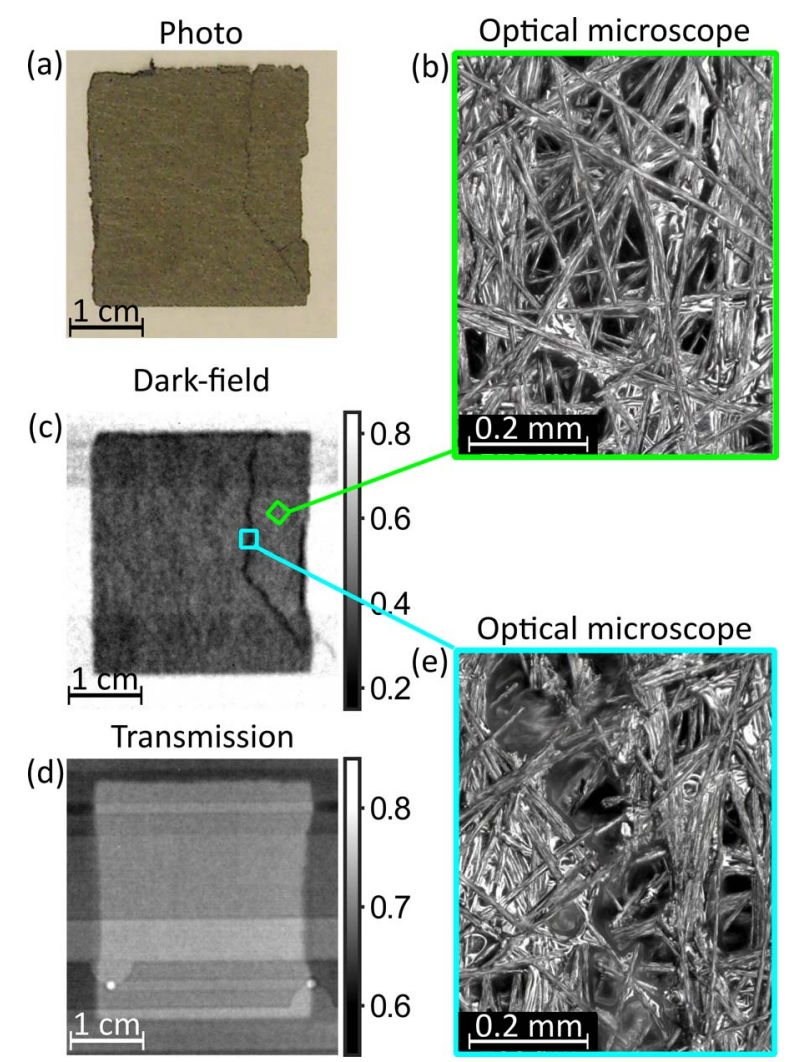

Figure 9. Visualized crack in a GDL (T00). (a) Photograph, (b) optical microscope image of an undamaged GDL area, (c) dark-field image, (d) transmission image and (e) optical microscope images of a damaged GDL area.

Visualization of GDL damage.-In this paragraph we show that neutron dark-field imaging is also able to visualize inhomogeneities in the GDL microstructure. Plain Toray-060 paper GDLs (T00) did not withstand the lateral compression of the rubber gasket during the experiments and cracked as shown in Figure 9. The crack can be described as a small void between ends of broken carbon fibers. This change of the microstructure (increase in $\mathrm{C}$-air interfaces) is visualized in the dark-field image (Figure 9c) whereas the crack is not visible in the transmission image (Figure 9d). The same crack is also visible in a photograph of the same GDL (Figure 9a) and in images taken with an optical microscope after the neutron imaging experiments. Figure $9 \mathrm{~b}$ shows the intact GDL fibers of a GDL area without damage (green box in Figure 9c), while Figure 9e shows the broken fibers of the crack (blue box in Figure 9c).

The cracked GDL that is shown in Figure 9 is shown in Figure 10 together with a second GDL of type T00, which also cracked during the experiment. The $\mathrm{H}_{2} \mathrm{O}$ thickness image (Figure 10a) calculated based on the transmission image is shown in comparison to the darkfield image of the two samples in the dry state (Figure 10b). It was not possible to fill the sample on the left with water over the entire area, because water only invaded the crack in the GDL, while the rest of the GDL stayed dry during the experiment (Figure 10a). Also in the GDL displayed at the right side of the figure, the two cracks are the main injection points, which bring water from the GDL area above the hydrophilic porous membrane to the rest of the GDL. But in contrast to the sample at the left, the GDL at the right is filled well with water over almost the whole area. The damaged GDL on the left shows, that in case water accumulates preferably in a crack, it might be possible to detect GDL defects with conventional transmission imaging. However, the sample on the right shows that water does not always preferentially accumulate in the crack, and in such a case the GDL damage may not be detected with transmission imaging. In addition, dark-field imaging may also allow for detecting different types of de-
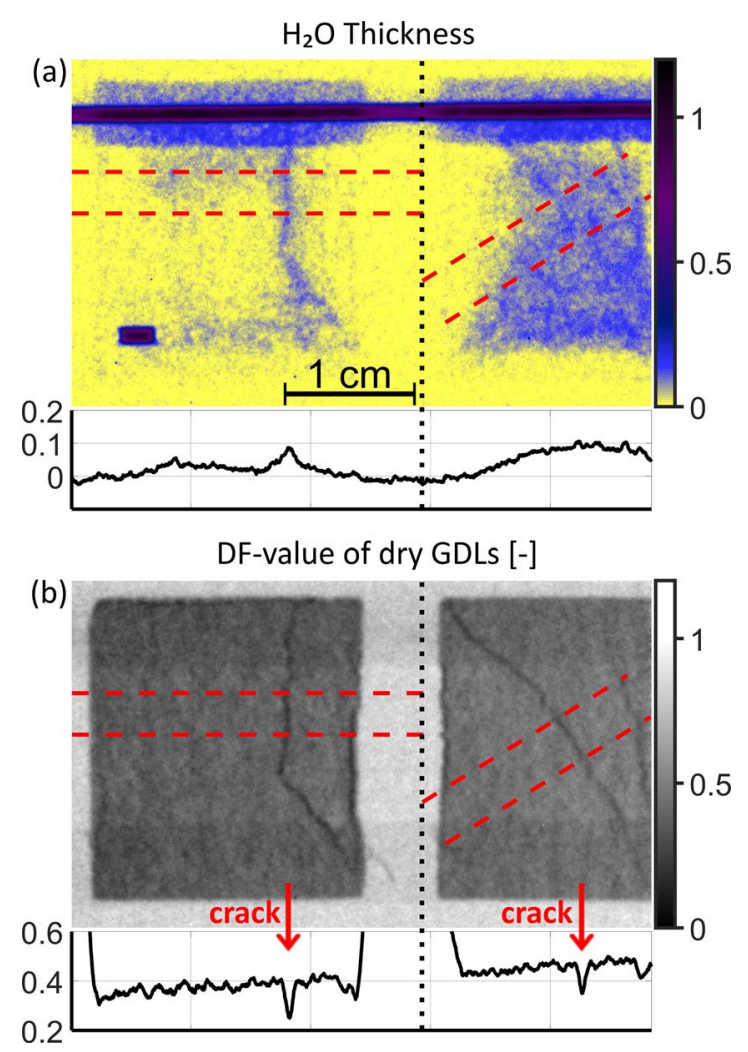

Figure 10. Two cracked GDLs of type T00. (a) Water $\left(\mathrm{H}_{2} \mathrm{O}\right)$ thickness based on transmission image (color coded). (b) Grey-scale dark-field image of dry GDLs. The dashed red lines in the image indicate the areas for which the profile is plotted below the image. The DF-value reductions due to the cracks are highlighted with red arrows.

fects, as for example locally broken fibers instead of long cracks. For such small local damages, it would be even more difficult to prove the presence of GDL damages indirectly with transmission imaging through the visualization of water accumulations. In summary, darkfiled imaging can provide in situ visualization of GDL damage for polymer electrolyte fuel cells. This could be of potential interest for freeze-thaw experiments and for degradation studies, where the damage induced by each cycle or over many hours could be observed without the need for disassembling the fuel cell.

\section{Conclusions}

We have demonstrated that neutron dark-field imaging allows for the selective visualization of water distribution in the GDL without the disturbance of water present in an overlapping $1 \mathrm{~mm}$ wide injection channel. This was done exploiting the fact that this technique is selectively sensitive to structures in a given size range, which scatter neutrons to ultra-small angles. A high contrast between a GDL filled with heavy water $\left(\mathrm{D}_{2} \mathrm{O}\right)$ and a dry GDL is obtained, while the water accumulated in the injection channel does not influence the dark-field value (DF-value). Measurements during different drying steps indicate a correlation between the DF-value and the quantity of water, though there is no direct proportionality relation. In future studies we aim to link theoretical knowledge with experimental results in order to better understand the measured DF-value of GDLs partially filled with water, and in particular its relation with the size and shape of water droplets, and the quantity of water present in the GDL. The fact that a thickness of around $50 \mu \mathrm{m}$ of water distributed in the GDL results in a different DF-value compared to the dry GDL supports that dark-field imaging will allow for analyzing GDL water during fuel cell operation without the perturbation by channel water inherent to transmission imaging. Because of the cost of $\mathrm{D}_{2}$ and $\mathrm{D}_{2} \mathrm{O}$, fuel cell 
operation with light water $\left(\mathrm{H}_{2} \mathrm{O}\right)$ is preferred. The smaller dark-field contrast between water filled and dry GDL obtained with $\mathrm{H}_{2} \mathrm{O}$ makes the reliable detection of water distributed in the GDL more challenging, but future optimizations of the imaging setup may help to obtain a suitable contrast-to-noise ratio. In regard to characterizing the water distribution in GDLs in operating fuel cells, the practicality of darkfield imaging has to be considered. The experimental results presented in this paper were all obtained with a long exposure time per image (75 s) and many phase steps (21 steps). The good neutron statistics obtained with these parameters allows for retrieving dark-field images with a low noise level. However, dark-filed imaging performed with the setup presented in this work bears the potential to provide the visualization of heavy water in GDLs with a reduced exposure time and reasonable high contrast-to-noise ratio. Optimization of the setup is expected to allow for a substantially reduced exposure time. In addition to the application for selective water visualization, we also demonstrated the ability of neutron dark-field imaging to identify damages in the GDL. This is of potential interest, for example, for conducting studies on in situ degradation of the GDL during freeze-thaw cycles.

\section{Acknowledgments}

The authors gratefully acknowledge Dirk Scheuble for building the experimental setup and for his support during experiments. This study was financially supported by the PSI CROSS initiative.

\section{ORCID}

T. J. Schmidt (1) https://orcid.org/0000-0002-1636-367X

P. Boillat (1D https://orcid.org/0000-0002-5683-8086

\section{References}

1. P. Boillat, P. Oberholzer, A. Kaestner, R. Siegrist, E. H. Lehmann, G. G. Scherer, and A. Wokaun, J Electrochem Soc, 159, F210 (2012)

2. P. Oberholzer, P. Boillat, A. Kaestner, E. H. Lehmann, G. G. Scherer, T. J. Schmidt, and A. Wokaun, J Electrochem Soc, 160, F659 (2013).

3. F. N. Büchi and P. Boillat, in Encyclopedia of Applied Electrochemistry, R. F. Savinell, K. Ota, and K. G. Editors, p. 1661, Springer Science + Busines Media LLC, New York (2014).

4. A. El-Kharouf, T. J. Mason, D. J. L. Brett, and B. G. Pollet, J Power Sources, 218 393 (2012).

5. M. V. Williams, E. Begg, L. Bonville, H. R. Kunz, and J. M. Fenton, J Electrochem Soc, 151, A1173 (2004).

6. J. Eller, J. Roth, F. Marone, M. Stampanoni, and F. N. Büchi, J Electrochem Soc 164, F115 (2017)

7. S. J. Normile, D. C. Sabarirajan, O. Calzada, V. De Andrade, X. Xiao, P. Mandal, D. Y. Parkinson, A. Serov, P. Atanassov, and I. V. Zenyuk, Materials Today Energy, 9, 187 (2018)

8. J. Roth, J. Eller, and F. N. Büchi, J Electrochem Soc, 159, F449 (2012).

9. P. Trtik and E. H. Lehmann, J Phys Conf Ser, 746 (2016).

10. D. S. Hussey, J. M. LaManna, E. Baltic, and D. L. Jacobson, Polymer Electrolyte Fuel Cells 16 (Pefc 16), 75, 245 (2016).

11. M. Grosse and N. Kardjilov, Neutron Imaging for Applications in Industry and Science, 88, 266 (2017).

12. A. Forner-Cuenca, J. Biesdorf, V. Manzi-Orezzoli, L. Gubler, T. J. Schmidt, and P. Boillat, J Electrochem Soc, 163, F1389 (2016).

13. J. Zhang, D. Kramer, R. Shimoi, Y. Ono, E. Lehmann, A. Wokaun, K. Shinohara, and G. G. Scherer, Electrochim Acta, 51, 2715 (2006).

14. J. Biesdorf, A. Forner-Cuenca, T. J. Schmidt, and P. Boillat, J Electrochem Soc, 162, F1243 (2015).

15. P. Stahl, J. Biesdorf, P. Boillat, J. Kraft, and K. A. Friedrich, J Electrochem Soc, 162 F677 (2015).

16. E. Coz, J. Théry, P. Boillat, V. Faucheux, D. Alincant, P. Capron, and G. Gébel, $J$ Power Sources, 331, 535 (2016).

17. D. Kramer, J. Zhang, R. Shimoi, E. Lehmann, A. Wokaun, K. Shinohara, and G. G. Scherer, Electrochim Acta, 50, 2603 (2005).

18. J. P. Owejan, T. A. Trabold, D. L. Jacobson, D. R. Baker, D. S. Hussey, and M. Arif, Int J Heat Mass Tran, 49, 4721 (2006).

19. M. A. Hickner, N. P. Siegel, K. S. Chen, D. S. Hussey, and D. L. Jacobson, J Electrochem Soc, 157, B32 (2010).

20. P. Oberholzer and P. Boillat, J Electrochem Soc, 161, F139 (2014).
21. J. P. Owejan, T. A. Trabold, J. Gagliardo, D. L. Jacobson, R. N. Carter, D. S. Hussey, and M. Arif, J Power Sources, 171, 626 (2007).

22. S. Gößling, M. Klages, J. Haußmann, P. Beckhaus, M. Messerschmidt, T. Arlt, N. Kardjilov, I. Manke, J. Scholta, and A. Heinzel, J Power Sources, 306, 658 (2016).

23. P. Oberholzer, P. Boillat, R. Siegrist, A. Kästner, E. H. Lehmann, G. G. Scherer, and A. Wokaun, Electrochem Commun, 20, 67 (2012).

24. P. Boillat, D. Kramer, B. C. Seyfang, G. Frei, E. Lehmann, G. G. Scherer, A. Wokaun, Y. Ichikawa, Y. Tasaki, and K. Shinohara, Electrochem Commun, 10, 546 (2008).

25. J. P. Owejan, T. A. Trabold, and M. M. Mench, Int J Heat Mass Tran, 71, 585 (2014).

26. P. Boillat, A. Iranzo, and J. Biesdorf, J Electrochem Soc, 162, F531 (2015).

27. C. Grünzweig, F. Pfeiffer, O. Bunk, T. Donath, G. Kühne, G. Frei, M. Dierolf, and C. David, Rev Sci Instrum, 79, 053703 (2008).

28. F. Pfeiffer, M. Bech, O. Bunk, P. Kraft, E. F. Eikenberry, C. Brönnimann, C. Grünzweig, and C. David, Nat Mater, 7, 134 (2008).

29. A. Hilger, N. Kardjilov, T. Kandemir, I. Manke, J. Banhart, D. Penumadu, A. Manescu, and M. Strobl, J Appl Phys, 107, 036101 (2010).

30. V. Revol, I. Jerjen, C. Kottler, P. Schütz, R. Kaufmann, T. Luthi, U. Sennhauser, U. Straumann, and C. Urban, J Appl Phys, 110, 044912 (2011).

31. M. Stampanoni, Z. T. Wang, T. Thuring, C. David, E. Roessl, M. Trippel, R. A. Kubik-Huch, G. Singer, M. K. Hohl, and N. Hauser, Invest Radiol, 46, 801 (2011).

32. T. H. Jensen, M. Bech, O. Bunk, T. Donath, C. David, R. Feidenhans'i, and F. Pfeiffer, Phys Med Biol, 55, 3317 (2010)

33. V. Revol, B. Plank, R. Kaufmann, J. Kastner, C. Kottler, and A. Neels, Ndt\&E Int, 58, 64 (2013)

34. T. Reimann, S. Muhlbauer, M. Horisberger, B. Betz, P. Böni, and M. Schulz, J Appl Crystallogr, 49, 1488 (2016).

35. W. Yashiro, S. Harasse, K. Kawabata, H. Kuwabara, T. Yamazaki, and A. Momose, Phys Rev B, 84, 094106 (2011).

36. M. Strobl, C. Grüenzweig, A. Hilger, I. Manke, N. Kardjilov, C. David, and F. Pfeiffer, Phys Rev Lett, 101, 123902 (2008).

37. C. Grünzweig, J. Kopecek, B. Betz, A. Kaestner, K. Jefimovs, J. Kohlbrecher, U. Gasser, O. Bunk, C. David, E. Lehmann, T. Donath, and F. Pfeiffer, Phys Rev $B, \mathbf{8 8}, 125104$ (2013)

38. M. Bech, O. Bunk, T. Donath, R. Feidenhans'l, C. David, and F. Pfeiffer, Phys Med Biol, 55, 5529 (2010).

39. B. Betz, R. Harti, M. Strobl, J. Hovind, A. Kaestner, E. Lehmann, H. Van Swygenhoven, and C. Grünzweig, Rev Sci Instrum, 86, 123704 (2015).

40. R. P. Harti, M. Strobl, B. Betz, K. Jefimovs, M. Kagias, and C. Grünzweig, Sci Rep-Uk, 7, 44588 (2017)

41. S. K. Lynch, V. Pai, J. Auxier, A. F. Stein, E. E. Bennett, C. K. Kemble, X. H. Xiao, W. K. Lee, N. Y. Morgan, and H. H. Wen, Appl Optics, 50, 4310 (2011).

42. F. Prade, A. Yaroshenko, J. Herzen, and F. Pfeiffer, Epl-Europhys Lett, 112, 68002 (2015).

43. M. Strobl, Sci Rep-Uk, 4, 7243 (2014).

44. W. Yashiro, Y. Terui, K. Kawabata, and A. Momose, Opt Express, 18, 16890 (2010).

45. M. Kagias, Z. T. Wang, K. Jefimovs, and M. Stampanoni, Appl Phys Lett, 110, 014105 (2017).

46. F. Yang, F. Prade, M. Griffa, I. Jerjen, C. Di Bella, J. Herzen, A. Sarapata, F. Pfeiffer, and P. Lura, Appl Phys Lett, 105, 154105 (2014).

47. K. W. Feindel, S. H. Bergens, and R. E. Wasylishen, J Power Sources, 173, 86 (2007).

48. T. Kotaka, S. Tsushima, and S. Hirai, Ecs Transactions, 11, 445 (2007).

49. I. Manke, C. Hartnig, N. Kardjilov, M. Messerschmidt, A. Hilger, M. Strobl, W. Lehnert, and J. Banhart, Appl Phys Lett, 92 (2008).

50. T. Arlt, W. Lüke, N. Kardjilov, J. Banhart, W. Lehnert, and I. Manke, J Power Sources, 299, 125 (2015)

51. P. Boillat, P. Oberholzer, B. C. Seyfang, A. Kastner, R. Perego, G. G. Scherer, E. H. Lehmann, and A. Wokaun, J Phys-Condens Mat, 23 (2011).

52. P. Boillat, G. G. Scherer, A. Wokaun, G. Frei, and E. H. Lehmann, Electrochem Commun, 10, 1311 (2008).

53. P. Oberholzer and P. Boillat, J Phys Chem C, 117, 19945 (2013).

54. A. Furrer, J. Mesot, and T. Strassle, Neutron Scattering in Condensed Matter Physics, p. 13, World Scientific (2009).

55. R. Andersson, L. F. van Heijkamp, I. M. de Schepper, and W. G. Bouwman, J Appl Crystallogr, 41, 868 (2008)

56. P. Boillat, E. H. Lehmann, P. Trtik, and M. Cochet, Current Opinion in Electrochemistry, 5, 3 (2017)

57. M. Cochet, A. Forner-Cuenca, V. Manzi-Orezzoli, M. Siegwart, D. Scheuble, and P. Boillat, Fuel Cells, 18, 619 (2018).

58. A. P. Kaestner, S. Hartmann, G. Kühne, G. Frei, C. Grünzweig, L. Josic, F. Schmid, and E. H. Lehmann, Nucl Instrum Meth A, 659, 387 (2011).

59. R. P. V. Harti, J., nGImagic/TaPy: TaPy 0.2, in (2017).

60. J. L. Russell, J. M. Neill, and J. R. Brown, Total Cross Section Measurements of $\mathrm{H}_{2} \mathrm{O}$, in, General Dynamics Corp., San Diego, CA (US) General Atomic Div. (1966).

61. J. I. M. Damián, J. R. Granada, D. V. Baxter, S. R. Parnell, and D. C. Evans, Nuovo Cim C-Colloq C, 38, 178 (2015).

62. R. P. Harti, C. Kottler, J. Valsecchi, K. Jefimovs, M. Kagias, M. Strobl, and C. Grunzweig, Opt Express, 25, 1019 (2017)

63. K. Merck, Merck KGaA, in, Merck KGaA, Darmstadt, Germany (2018). 